\title{
Exploration of Platform Construction for Innovation Talents Cultivation of Information Science
}

\author{
Kewen Liu, ${ }^{1, *}$, Hongxia Xiong ${ }^{2}$, Zhiqiang Guo ${ }^{1, a}$ \\ ${ }^{1}$ School of Information Engineering, \\ Wuhan University of Technology, \\ Wuhan, 430070, China. \\ *Email: liukewen@whut.edu.cn
}

\author{
Qingsong $\mathrm{Ai}^{1}$, Rong Zhou ${ }^{1}$ \\ 2School of Civil Engineering and Architecture, \\ Wuhan University of Technology, \\ Wuhan, 430070, China. \\ aguozhiqiang@whut.edu.cn
}

\begin{abstract}
The current state and the existing problems of innovation talents cultivation in Chinese universities are analyzed in this paper. Moreover, the significance to cultivate innovative talents under the new age is explained. Training objectives of Information science innovation talents cultivation are determined based on the analysis about the characteristics of information industry and the connotation of innovation talents information science. Combining with practice status of innovative training model of communication engineering in Wuhan University of Technology, this paper proposes the strategy to build innovative talents training platform for information science. The operation progress and results of innovative talents training platform show its feasibility and replicability.
\end{abstract}

Keywords-information science; innovation talents cultivation; cultivation platform

\section{INTRODUCTION}

"The Country's Medium and Long-term Science and Technology Development Plan Outline (2006-2020)” clearly put forward the main strategic objectives to build the innovative country. Also, it stressed that we should deepen education reform and promotes quality education and innovative education to cultivate talents with high-quality of all types and at all levels. Innovation is not only the soul for a nation's progress but also the inexhaustible driving force for the prosperity of a country. A large number of compound talents with innovative spirit and practice ability are needed for the construction of national innovation system. Therefore, the cultivation of innovative talents is the important task for our country's education departments especially that institutions of higher learning in our country which bearing the important era responsibility and historical mission.

\section{The SignifiCANCE Of CUltivating InNOVAtive TALENTS}

A. It makes contribute to improve the country's capacity of independent innovation and enhance national competitiveness.

A factor that affects the national competitiveness is the strength of the independent innovation ability. With a comprehensive analysis about the ranking of Chinese competitiveness in previous years, we can see the low participation of new technology and poor self-innovation in China. And the future core competitiveness of the country largely depends on the college students' creativity.

\section{B. It helps to improve the productivity level and economic efficiency of the society.}

The backward of economic for countries represents on low labor productivity and management level. The improvement of a country's science and technology and education level is essential for the improvement of productivity level. And college students must undertake the important task of national science and technology development[1].

\section{It contributes to improve the level of scientific research and obtain more scientific research achievements.}

So far the top three countries obtaining the largest number of Nobel Prize are the United States, Britain and Germany. Especially in the past 30 years, Americans had accounted for more than half among the total number of the Nobel Prize in physics, chemistry, physiology or medicine. However, China missed almost all the world's various scientific awards. Throughout the world development, there isn't a big country can develop without the development of science and technology and the continuous cultivation of innovative talents.

\section{The CURRENT SituAtion AND EXISTING Problems of CULTIVATING INNOVATIVE TALENTS IN CHINESE UNIVERSITIES}

A. Orientation of cultivating goals in Universities of different levels is fuzzy

Wang Hongjun who graduated from Jilin FAW technical school made a series of innovations in the car repair by continuously learning and summarizing from practice. He had won the national science and technology progress second prize and the China youth science and technology award. And such example explains that innovative achievements can be obtained by ordinary people to scientists, and different levels of schools are both likely to cultivate innovative talents. The lack of system, the absence of management, lack of resources and blurred orientation of cultivating target may represent the current situation of Chinese universities. The cultivate talents 
trained in different levels of schools are mostly widely adaptive talent, but the personalized feature of students is ignored and which lacks of creativity and the ability of scientific research.

\section{B. The conservatism of curriculum design and lack of strength and depth in reform}

The structure of current curriculum mainly encompasses normal basic courses, discipline basic courses, professional courses, and common courses. The outline of the curriculum seems to be clear. However, it has a drawback. The types of contents in basic courses are too simple and the contents are obsolete. The professional courses are set in a narrowly professional objective. Relation between liberal arts and science and engineering is weak. Meanwhile, professional guards are closed and cultivating comprehensive qualities of students is neglect. Meanwhile, the textbooks cannot catch up with the pace of changing times and contents of which repeat too much and are out of date.

\section{The simple teaching method and evaluation mechanism}

The teaching mode in universities mostly looks like teaching off a blackboard and "cramming". Students are just on-fed the basic knowledge and no cultivation of students' independent thinking are considered by teachers. Then students become "reading machine" which is just good at memory and the examination. Evaluation way based on written examination is to test student's memory ability on knowledge, which only can simply repeat the previous ideas and the final conclusion of books and don't dare to challenge authority[2]. While, teaching management in universities is rigid and the cultivate one in students evaluation mechanisms is short. Various evaluation ways present a strong utilitarian and ignore the characteristics of innovation.

\section{Training system of innovative talents is incomplete and the environment is not harmonious}

At present, score is still regard as the absolute standard in college admission system. So the value of orientation and objectives of pre-university education are to emphasize the test and the process of teaching. The environment may cause stereotyped thinking pattern for students and restrict the formation of creativity. The existing cultivating system in our country, failed to consider the students' creativity in many ways, generally thinks that the cultivation of innovative talents is just the job for some departments, some courses or sometime and no complete long-term plan is exist.

Overall, there are some problems existing in innovative talent training pattern of universities. For example, education concept is not updated in time, education mode is relatively backward, teaching quality and talent standard evaluation system are not scientific, there is no good atmosphere of encouraging students to exert personality and innovate boldly and especially the combination of teaching and scientific research is not close. Such problems, seriously restrict the cultivation of innovative talents, result the strong ability of acquiring knowledge, grasping the book knowledge, abstract thinking and deriving data, but the weak one of researching and creating, solving practical problems, using knowledge synthetically and expression in language and writing. Therefore, researching and exploring the efficient, scientific and practical innovative talent cultivating pattern to cultivate innovative talents with high-quality, thick foundation, strong ability and wide caliber rapidly[3-4] for our country, is the realistic problem that needs to be solved by the current university education teaching reform and university's sustainable development.

\section{THE CHARACTERISTICS OF INFORMATION INDUSTRY ERA AND INFORMATION SUBJECT}

With the coming of knowledge economy age, information industry has changed the way of human's production and life. And, it is also the most intensive, rapid, widely used competitive and concentrated industry in the modern technology. Many countries have put strengthening information technology innovation as the national strategic position and there is a big increase in spending on research to grab the commanding heights of science and technology and win the initiative of the development.

To narrow the gap with the developed countries and realize industrialization as soon as possible, China has establish the strategic objectives of using informationization to drive industrialization and using industrialization to promote informationization to realize the process of industrialization and informationization. The key to achieve the goal is to cultivate a batch of advanced electronic engineering talents and engineering experts that outstanding and meet the requirements of times development for electronic information technology innovation and scientific research [5]. The innovative talents of information specialty have high requirement to basic specialized knowledge and solid basic knowledge. Also, the basic theory of electronics and information engineering is needed. The master of the electronic technology, computer technology, network and information system engineering design and management knowledge and the ability for certain scientific research and innovation are also needed. Meanwhile, it requires that the good electronics and information engineering practice of basic training, understanding the subject application prospects and the latest developments, the abilities of design, development, using integrated circuit devices and information system integration, grasping foreign languages, reading specialized foreign language books and periodicals and good scientific research innovation ability[6-7].

\section{EXPLORATION AND PRACTICE OF BUILDING PLATFORM FOR INNOVATIVE TALENTS TRAINING OF INFORMATION SCIENCE IN WUHAN UNIVERSITY OF TECHNOLOGY}

Communication engineering of Wuhan University of Technology was set up in 1996 and "Communication and information system", obtained "information and communication engineering” doctoral degree conferral right, had been approved for key discipline of Hubei Province in 2003. It became brand professional of Hubei Province in 2007 and a national characteristic specialty Ministry of Education approved to construct in 2008. Communication engineering teaching team had become the national teaching team.

In recent years we focus on "what kind of students to cultivate" and "how to cultivate students" to conduct research 
and practice discipline about building information system for cultivating high quality and creativity. Schools undertake the education reform project of Ministry of Education and the provincial education department and the research results has been cured to school teaching programs and training programs in order to construct a innovative training system which the main content of the information subject are "setting a goal, taking two kinds of measures, building three major systems and creating four kinds of environment" and "Multi-level, threedimensional and open innovative practice teaching system and closed-loop quality control and guarantee system information such as discipline innovation talent training platform.

According to the requirements of the development of industry and the actual situation of universities, a distinctive professional training system should be formulated. This system can take first-class doctor degree discipline of information and communication engineering and provincial brand of professional communication engineering as the support, "three full” education system as the protection, the enterprises as the basis and research as the direction. Also, the school should develop the "on-tea two-level three-brand four-platform" (excellent teams, the high level of multimedia teaching and bilingual teaching, professional brand, quality curriculum, excellent teaching material, four characteristic practice teaching platform, the modern communication system based on embedded technology and practice platform of information processing, the practice platforms of program-controlled switching and access network, practice platforms of wireless communications and mobile communications, practice platforms of streaming media communications) as the characteristic for building of professional development and training targets.

\section{A. Re-recognition and Re-design of Training Ideas and Notion of creative talents in Information Specialty}

1) The concept of engineering education should run through the creative talents teaching and students' engineering consciousness, solving practical problems on sites and application design capabilities should be considered.

2) Teaching contents and curriculum system should reflect the mainstream technology and the latest developments in ICT industry. And, in the form of teaching organization, practical aspects, management system and operation mechanism, it must be bold and innovative.

3) The cultivated students should have reasonable culture of knowledge structure, excellent professional qualities, the design level superb and comprehensive ability to highlight, a solid mathematical science and engineering base and master design ideas and methods of information and communication engineering. Meanwhile, they should have a strong liberal arts combined with multidisciplinary cross-project awareness and good project organization and leadership.

4) The ability of autonomous learning and the inquiry learning should be strengthened. The ability to solve problems in complex engineering technical for students should be feasibly enhanced.
5) The personnel training evaluation system that is participated by the schools, employers, industry sector and teaching department, should be established.

\section{B. Building Practical Teaching Platform of "Analog Environment Project”}

Since our university carried out the innovative talent training plan, the cooperation with employers has been emphasized and a new way of running a school co-working with industry and research institutions has been explored. Meanwhile, the cooperative mechanism has been built. Through the deep collaboration with the famous enterprises in the relevant area and the analysis of the requirement of current industrial for engineering education, we attempt the multistandards which including the construction of internal and external experiments, practical training facilities and venues, and more and better opportunities for the staff and the students to participate in the engineering practice. To be more specific:

1) The "Fiber Optic Sensing Technology and Information Processing” in our university is a key laboratory of the ministry of education and "Digital Manufacturing" of Hubei province. The key laboratory can provide an opportunity of internships, experiments and engineering training for undergraduates. And the postgraduate can do research in the laboratory. The collaboration shall be enhanced taking advantages of the research-innovation cohesion of the key labs and the radiant influence as a model port.

2) Our university and Wuhan Zhong Yuan Electronics Company co-built a national engineering practice education center, which can simulate factory environment and looked as a factory. Each laboratory in the center was different workshops and the production plant is consists of the experimental device that made up of small control system. The whole system employed the network control system and it was typical industrial production simulation factories which consist of field control layer, shop floor scheduling, and plant-level management to finish the virtual and reality control in the industrial process. The center adopts the business management model for student. It strengthened the various aspects of design and implementation of communication engineering technology and focus on cultivate the student's professional knowledge and ability of engineering practice.

3) Wuhan university of technology has signed a agreement that college-enterprise cooperation in school teaching running with some known domestic enterprises, such as the Wuhan Posts and Telecommunications Research Institute, Wuhan HuaGong ZhengYuan Photon Technology Company Limited, Wuhan WeiChuang Photoelectric Company Limited, Shanghai MingBo Communication Technology Company Limited, Shenzhen KaiRui Optical Communication Technology Company Limited and so on, which can instruct students in social practice, technological innovation, professional practice, graduation design (thesis) writing, research capacity training and some other practice teaching activities. Both schools and enterprises will occasional carry out technical seminars, exchange of experiences, etc., helping students accumulate working experience, promoting innovation practice ability and 
providing a broad platform for the students belongs to the majors who can take part in the social practice.

\section{Expand of research and teaching combine innovative practice base}

Firstly, based on a combination of scientific research and teaching philosophy, a team of teachers with creativity, technological innovation and strong innovative has been built.

Innovative teachers should change their concepts of education. Under the traditional inheritance of innovative education teachers should strengthen the new ideas to establish innovative education conception and holistic knowledge education to encourage students to put forward new ideas and new distinctive insights. They also should focus on the development of personality and exercise for students. Meanwhile, teachers should introduce students to the frontiers of science and research and guide students to choose topics, find a breakthrough, gather information, and write research reports according to their own research and experience. So the students can be trained and get results in research practice from introduce of teachers. The traditional education may be transformed to innovative education.

Secondly, the research projects should be taught in the class. Teachers should organize the creative courses which combining with scientific research and innovative teaching. The methods and forms of scientific research should be adopted in the teaching process in theory and skills. The introduction of scientific research in the teaching process and arranging scientific research tasks which can guide students to master course content in the course of conducting research activities. At the same time, students can acquire the knowledge and the ability and quality also can be greatly improved.

Finally, the teaching content should be scientific. Teachers should integrate the latest scientific research into teaching process actively and selectively to keep the teaching content frontier and times. Furthermore, it can help students open their mind and increase their creative consciousness. The ability to combine theory with practice, creativity and entrepreneurship of students will be improved by this way and they can lay a solid foundation for employment, entrepreneurship or scientific research of undergraduate in the future.

\section{CONCLUSION}

The proposed training objectives, knowledge and ability system, school-enterprise cooperation training programs, curriculum practical teaching reform, ways to achieve training objectives and quality assurance monitoring system and other aspects of exploration and practice, which has been carried out at communication engineering from 2010 to 2014. With systematic innovation training and teaching competition, as a platform to strengthen the culture of engineering practice and innovation ability of students which will the feature of information profession training in our school. Focusing on practical training program, the National "Challenge Cup" extracurricular science and technology contest, national and provincial "Undergraduate Electronic Contest" students mechanical innovation competition, Mathematical Contest in Modeling, College English Contest and the "Business Plan" competition and students' energy saving competitions and other activities, scientific research and industrial base and supporting innovative research to guide the innovative activities for students, which continue to improve the ability of engineering practice.

\section{ACKNOWLEDGMENT}

This research was supported by Education and Research Project(No.2014110) funded by the Hubei Education of Department.

\section{REFERENCES}

[1] “Long-term Education Reform and Development Plan”(2010-2020).(In Chinese)

[2] Lin Jian: "Education Excellence engineer training program professional training program for a further study," "Higher Engineering Education Research”, 2011(4).(In Chinese)

[3] "The Ministry of Education on the implementation of a number of opinions excellent engineer education and training programs," "teach high [2011] .”(In Chinese)

[4] Ministry of Education: "National Engineering Practice Education Center Management (tentative)” Draft), 2011.(In Chinese)

[5] FU Yuanqian: "Exploration of Electronic Science and Applied Undergraduate Experimental Teaching Reform of technology", "Higher education”, 2008(4).(In Chinese)

[6] Chen Jing, Hu Jianxiong: "innovation-oriented country of Engineering Education Reform” [M] Beijing, China Renmin University Press, 2006.(In Chinese)

[7] Yan Liqin: "Innovative Education" [M] Beijing, Beijing Education Science Press, 1999.J. Clerk Maxwell, A Treatise on Electricity and Magnetism, 3rd ed., vol. 2. Oxford: Clarendon, 1892, pp.68-73.(In Chinese) 